\title{
The Regional Seas Programme of UNEP
}

\author{
by \\ PATRICIA A. BLISS-GUEST, M.Sc.(LSE) \\ Programme Officer, Regional Seas Programme Activity Centre, \\ United Nations Environment Programme (UNEP), Palais des Nations, \\ 1211 Geneva 10, Switzerland \\ $\&$ \\ STJEPAN KECKES, Ph.D.(Zagreb) \\ Director, Regional Seas Programme Activity Centre, United Nations Environment Programme (UNEP), \\ Palais des Nations, 1211 Geneva 10, Switzerland.
}

\section{INTRODUCTION}

It is now almost ten years since the United Nations Conference on the Human Environment (Stockholm, 5-16 June 1972) adopted its Action Plan for the Human Environment (United Nations, 1973). In the light of the results of the Stockholm Conference, the United Nations General Assembly 'decided to establish' the United Nations Environment Programme (UNEP) to 'serve as a focal point for environmental action and coordination within the United Nations system' (General Assembly resolution (XXVII) of 15 December 1972). In that resolution, the organizations of the United Nations system were invited 'to adopt the measures that may be required to undertake concerted and coordinated programmes with regard to international environmental problems', and the 'intergovernmental and nongovernmental organizations that have an interest in the field of the environment' were also invited 'to lend their full support and collaboration to the United Nations with a view to achieving the largest possible degree of cooperation and coordination'.

Although many of the present-day environmental problems are of a global nature, UNEP chose to deal with certain of them through a regional approach. UNEP's Regional Seas Programme is one of several examples of this approach, and it will be reviewed in this article.*

Problems related to the marine environment have not altered greatly in the past decade, but general perceptions of the main threats and corresponding solutions have markedly changed on the basis of knowledge accumulated during that period (Global 2000 Report to the President, 1980; Review of the Health of the Oceans, in press). Although there is still considerable interest in levels of contamination in the open ocean and in major oceanic processes, the danger of the open ocean becoming severely polluted is now considered to be less acute than was formerly thought, and it is evident that existing problems, and the first effects of new ones, are most likely to arise in waters that are situated close to land. Attention is therefore being concentrated on protecting

*Two other notable examples are described in the preceding and next-but-one following articles. - Ed. the health of the coastal waters, especially in enclosed and semi-enclosed seas.

The continued growth of human settlements along the coast, the increase in coastal recreation, the concentration of industrial development in coastal areas, and the wealth of exploitable living marine resources in coastal waters, ${ }^{+}$all justify the concern that is currently felt for the quality of the coastal marine environment and its resources. The application of environmentallysound management practices in coastal and maritime activities is now accepted as the key to safeguarding the marine environment. By this means, unplanned or illplanned land-use practices, the irrational exploitation of natural resources, and the pollution to which they incidentally give rise, can be avoided.

Emphasis on the concept of management reflects a critical change from earlier concern that the oceans had to be preserved unchanged. Management implies userational use. For example, when deciding on appropriate waste treatment and disposal practices, the wastereceiving capacity of the sea is clearly recognized as an asset which may be used for certain types of waste.

\section{APPROACH}

The Stockholm Conference adopted, inter alia, the principle that 'the marine environment and all the living organisms which it supports are of vital importance to humanity', and recognized that 'proper management is required and measures to prevent and control marine pollution must be regarded as an essential element in this management'. Furthermore, the Stockholm Conference recommended that Governments take early action to adopt "effective national measures for the control of all significant sources of marine pollution, including landbased sources, and concert and coordinate their actions regionally and where appropriate on a wider international basis'.

The early meetings of the Governing Council of UNEP endorsed the regional approach to the control of marine

$\boldsymbol{t}_{A}$ referee adds the points of primary productivity and easy accessibility. - Ed. 
pollution and the management of marine and coastal environments, and requested the development of regional action plans for areas of the ocean where such plans did not yet exist. Consequently, in 1974, the Regional Seas Programme of UNEP was initiated. Subsequent meetings of the Governing Council have repeatedly reconfirmed its endorsement of the regional strategy.

Although it is only within the last few years that UNEP's Regional Seas Programme has evolved into a large and complex international programme supported by a number of specialized agencies of the United $\mathrm{Na}$ tions system and other intergovernmental and nongovernmental organizations, the advent of regionalism in marine affairs goes back to the early years of this century. The International Council for the Exploration of the Sea (ICES), established in 1902, is certainly the oldest international organization involved in the study of the marine environment. In 1919, the International Commission for the Scientific Exploration of the Mediterranean Sea (ICSEM) was founded, on the model of ICES, and latterly, in many other regions of the world, regional bodies and programmes have been established in order to deal with problems related to the marine environment.

The overall strategy followed in UNEP's Regional Seas Programme (for the description of comparable programmes sponsored by other organizations, see UNEP, $1982 a$ ) includes four main components:

1) Promotion of international and regional conventions, guidelines, and policies, for the control of marine pollution and for the protection and management of marine and coastal resources;

2) Assessment of the state of marine pollution, of the sources and trends of this pollution, and of the impact of the pollution on human health, marine ecosystems, and amenities;

3) Coordination of efforts with regard to the environmental aspects of the protection, development, and management, of marine and coastal resources, and

4) Support for education and training efforts to make possible the full participation of all countries in the protection, development, and management, of marine and coastal resources.

The Regional Seas Programme is conceived as an action-oriented programme having concern not only for the consequences but also for the causes of environmental degradation, and encompassing a comprehensive approach to preventing and abating environmental problems through the proper management of marine and coastal areas. Each regional action plan is formulated according to the needs of the region as perceived by the Governments concerned. It is designed to link assessment of the quality of the marine environment and the causes of its deterioration, with activities for the management and development of the marine and coastal environments. The action plans promote the parallel development of regional legal agreements and of action-oriented programme activities.

As each regional programme is aimed at benefiting the States of that region, Governments are involved from the very beginning in the formulation of an action plan.
After adoption of this plan, its implementation is carried out, under the overall authority of the Governments concerned, by national institutions nominated by their Governments. UNEP acts as an overall coordinator for the development and implementation of regional action plans-although, in some cases, this role is limited to the initial phase of the activities.

In the framework of UNEP, a Regional Seas Programme Activity Centre was established in 1977 to coordinate the efforts of those involved in the Regional Seas Programme.

Financial support for the regional programmes is initially provided by UNEP and other international and regional organizations. As a programme develops, however, it is expected that the Governments of its own region will assume increasing financial responsibility for its implementation, through specific regional trust funds or other suitable mechanisms. Additional assistance continues to be made available by other bodies within the United Nations system--e.g. for technical assistance and provision of expert advice, training, or technical support. The bodies concerned are encouraged to provide this assistance as part of their normal programmes, and to finance activities through their own funding mechanisms.

\section{ACHIEVEMENTS}

The Regional Seas Programme at present comprises ten regions (Fig. 1), and has over 120 coastal States participating in it. Since it was initiated in 1974, action plans for eight of the regions have been adopted at the level of regional intergovernmental meetings or conferences of plenipotentiaries, along with five related regional conventions for the protection of the marine and coastal environments. The adoption of an additional regional convention is likely towards the end of 1982 , and the adoption of action plans for the two remaining regions is envisaged for late 1983 or early 1984 . UNEP was designated as the secretariat for five of the adopted action plans (though for one of them only on an interim basis) and for three of the regional conventions (for one of them only on an interim basis).

The state of development of each of these regional action plans and certain specific achievements are reviewed in some detail below, the numbers referring to those on the map (Fig. 1).

\section{The Mediterranean Action Plan}

This Action Plan was adopted at an Intergovernmental meeting in Barcelona, Spain, during 28 January-4 February 1975 (UNEP, 1975; Johnson, 1975-see also Thacher, 1976; Ress, 1978). Geographically it covers the Mediterranean Sea proper between the Straits of Gibraltar and the Straits of the Dardanelles together with the adjacent coasts, the total extent of which is defined according to the activity by the Governments of Spain, France, Monaco, Italy, Yugoslavia, Albania, Greece, Turkey, Cyprus, Syria, Lebanon, Israel, Egypt, Libya, Malta, Tunisia, Algeria, and Morocco. The action plan includes: 


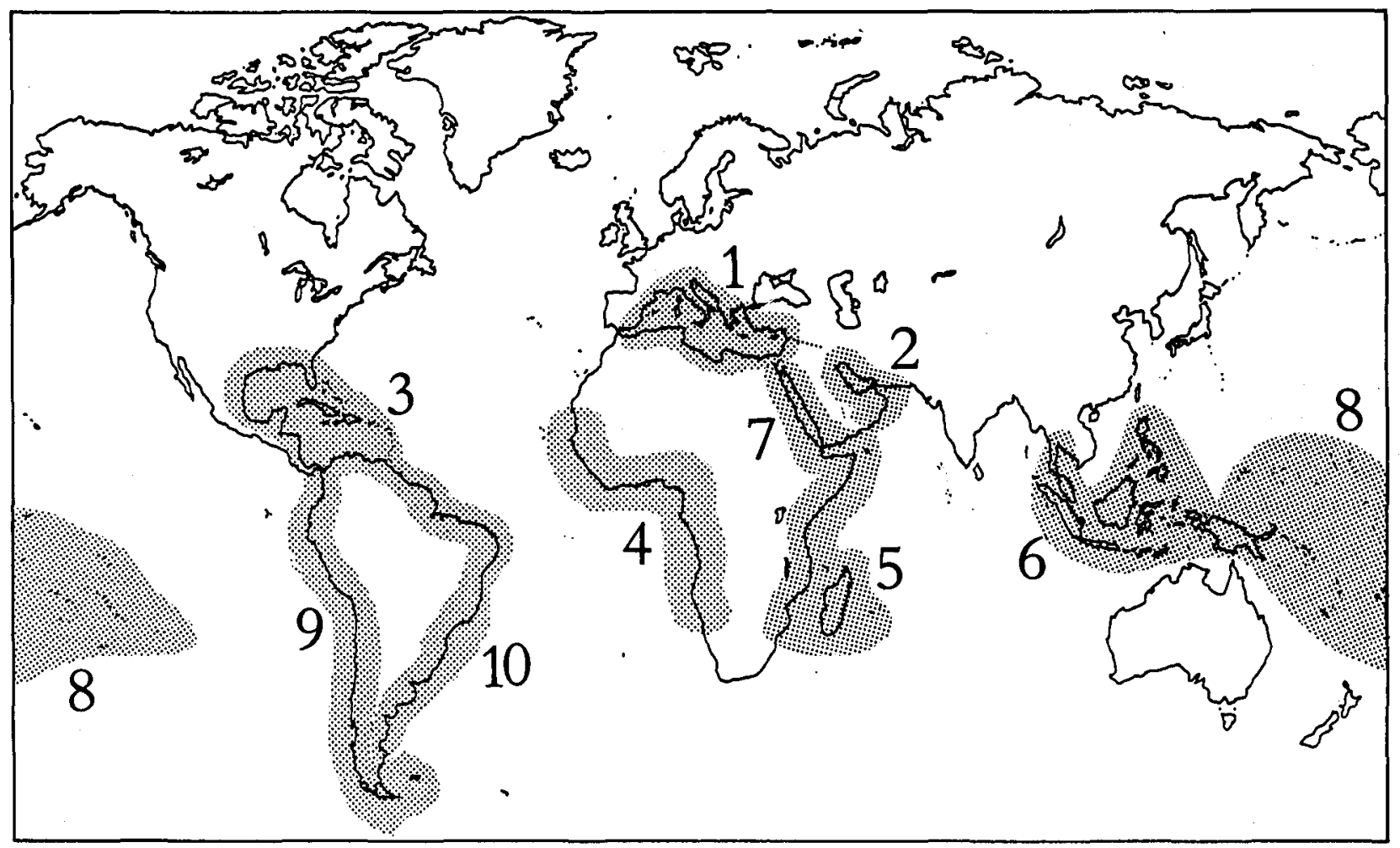

1. Mediterranean Region

2. Kuwait Action Plan Region

3. Caribbean Region

4. West and Central African Region

a) Integrated planning of the development and management of the resources of the Mediterranean Basin;

b) A coordinated programme for research, monitoring, and exchange of information, together with assessment of the state of pollution and of protection measures (MEDPOL*);

c) A framework convention and related protocols, and

d) Institutional and financial arrangements supporting the implementation of the action plan.

The Convention for the Protection of the Mediterranean Sea against Pollution (Barcelona Convention), the Protocol for the Prevention of Pollution of the Mediterranean Sea by Dumping from Ships and Aircraft, the Protocol concerning cooperation in Combating Pollution of the Mediterranean Sea by Oil and other Harmful Substances in Cases of Emergency, were signed at a conference of plenipotentiaries in Barcelona in February 1976 (UNEP, 1982c). The Convention and its protocols entered into force in 1978. An additional protocol (Protocol for the Protection of the Mediterranean Sea against Pollution from Land-based Sources) was signed at a conference of plenipotentiaries at Athens in May 1980 (Ibid.), and a Protocol concerning Mediterranean Specially Protected Areas is expected to be signed at Geneva in March $1982^{\dagger}$. The Convention and its protocols apply to the maritime waters of the Mediterannean Sea proper, includ-

${ }^{*}$ Coordinated Mediterranean Pollution Monitoring and Research Programme.-Ed. ing its gulfs and seas, bounded to the west by the meridian passing through Cape Spartel lighthouse, at the entrance of the Straits of Gibraltar, and to the east by the southern limits of the Straits of the Dardanelles between Mehmetcik and Kumkale lighthouse'.

In the framework of the Action Plan, the pilot phase of the Coordinated Mediterranean Pollution Monitoring and Research Programme (MEDPOL) was carried out by 86 national laboratories in 16 Mediterranean States during the period 1976-81. It included baseline studies and monitoring of oil and petroleum hydrocarbons, of metals (particularly mercury), of DDT, PCBs, and other chlorinated hydrocarbons, as well as research on the effects of pollutants on marine organisms' communities and ecosystems, study of the problems of coastal transport of pollutants, and coastal waters' quality control.

A thorough survey of pollutants from land-based sources was prepared and used in negotiating the Protocol of the Mediterranean Sea against Pollution from Land-Based Sources. The intercalibration of analytical methods used for organochlorine residues and metals

\footnotetext{
$\dagger_{\text {Following the Intergovernmental Meeting on Mediterranean }}$ Specially Protected Areas, as presaged by Adrian Phillips \& $\mathrm{Dr}$ Pierre Hunkeler in Environmental Conservation, 8(1), pp. 76-7, 1981. Actually the Protocol was adopted only when this paper was in proof - by a conference of plenipotentiaries of the Contracting Parties to the Barcelona Convention-on 7 April 1982, being immediately signed by eight of the Contracting Parties (Mediterranean States). - Ed.
} 
was organized, as was the maintenance (regular and emergency services) of oceanographic and analytical equipment.

In 1981 the contracting parties to the Barcelona Convention endorsed a long-term (1981-91) pollution monitoring and research programme (MEDPOL: PHASE II) covering four different and complementary monitoring activities: monitoring of sources of pollution; monitoring of coastal areas including estuaries; monitoring of offshore reference areas; and monitoring of transport of pollutants through the atmosphere. Twelve research projects - ranging from the development of reference methods and environmental quality criteria to studies of basic oceanographic processes and toxicity, carcinogenicity, and epidemiology of selected pollutants of special relevance to the Mediterranean region-were also approved as part of MEDPOL: PHASE II.

Through MEDPOL, environmental quality criterianeeded for harmonized, region-wide management of environment and pollution control, as required by the Barcelona Convention and its protocols - are being developed. They include microbiological criteria for recreational and shellfish-growing waters, and also criteria on mercury in seafood. In both these connections, the recommendation is for a less stringent standard than is applied today (theoretically) in most of the Mediterranean States.

A 'Blue Plan' calls for systematic surveys of major development and environmental protection activities by Mediterranean States, and for the development of actionoriented alternative development policies based on the findings of these surveys.* There is also a 'Priority Actions Programme' which focuses on the application of sound environmental practices that require immediate action in selected priority areas: e.g. protection of soil, management of water resources and of living resources and aquaculture, development of renewable sources of energy, and human settlements and tourism.

In 1976 the Regional Oil-Combating Centre (ROCC) was established in Malta to further the objectives of the Protocol on Cooperation in Combating Pollution of the Mediterranean Sea by Oil and other Harmful Substances in Cases of Emergency. The objectives of this ROCC are to facilitate cooperation among the Mediterranean States in order to combat massive pollution by oil, to assist the States in the development of their own national capabilities, and to facilitate information exchange, technological cooperation, and training.

UNEP was designated as the secretariat of the Action Plan and the Barcelona Convention.

*See also the account published in Environmental Conservation, Vol. 4, No. 2, p. 153, Summer 1977, which explains that "The "Blue Plan" is an outgrowth of the Action Plan... The objective of the "Blue Plan" is to assist the Governments of the Mediterranean countries in identifying common problems and in reaching decisions that would promote rational resource management and sustainable development of the region while avoiding further environmental degradation. UNEP [acts as] coordinator, with each of the participating countries designating a national focal point for programme activities'.-Ed.

\section{The Kuwait Action Plan}

This Action Plan was adopted at a conference of plenipotentiaries at Kuwait in April 1978 (UNEP, 1978). Geographically it covers the sea area that is bounded in the south by rhumb lines (specified in the Kuwait Convention) together with the adjacent coastal areas as identified by the Governments of Bahrain, Iran, Iraq, Kuwait, Oman, Qatar, Saudi Arabia, and the United Arab Emirates (cf. Fig. 1). The extent of the 'coastal' area in each instance depends on the type of activities to be carried out.

Similarly to the Mediterranean Action Plan, the Kuwait Action Plan has environmental assessment, environmental management, and legal, components, as well as provisions for institutional and financial arrangements supporting their implementation.

At the same conference the Regional Convention for Cooperation on the Protection of the Marine Environment from Pollution (Kuwait Convention), and the Protocol concerning Regional Cooperation in Combating Pollution by Oil and other Harmful Substances in Cases of Emergency, were signed. Both legal instruments entered into force in 1980 . The Convention applies only to the sea area of the region.

UNEP was designated, on an interim basis, as the secretariat of both the Action Plan and the Convention. According to the provisions of the Convention, a Regional Organization for the Protection of the Marine Environment (ROPME) was established and assumed responsibility for the secretariat functions in early 1982 . It is situated in Kuwait.

The first projects of the Action Plan were begun in 1979 and included surveys of environmental problems, baseline studies of pollution, and oceanographic studies. These are currently being implemented as a pilot phase which will end in December 1983. Appropriate steps have been taken to ensure compatibility of data generated through these projects with data developed in other regional programmes, through the adoption of common methods of sampling and analysis as well as through the intercalibration of analytical methods.

\section{The Caribbean Action Plan}

This Action Plan was adopted at an intergovernmental meeting at Montego Bay, Jamaica, in April 1981 (UNEP, 1981a). Geographically, it covers the insular and coastal States and Territories of the Caribbean Sea and the Gulf of Mexico-including the Bahamas, Guyana, Surinam, and the French Department of Guiana, as well as the waters of the Atlantic Ocean adjacent to those States and Territories (cf. Fig. 1).

The Action Plan places a strong emphasis on the links between the environmental assessment and environmental management components. It also defines supporting institutional and financial arrangements. Regional projects of high priority that are expected to be carried out in the initial phase of the action plan include watershed management, oil-spill control, public awareness campaigns, and environmental impact assessment. 
Negotiations are under way for a Convention for the Protection and Development of the Marine and Coastal Environment of the Wider Caribbean Region, and on a Regional Agreement concerning Cooperation in Combating Oil-spills. The adoption of these legal instruments is expected in late 1982 or early 1983.

UNEP was designated as the secretariat of the Action Plan.

\section{The West and Central African Action Plan}

This Action Plan was adopted at a conference of plenipotentiaries at Abidjan, Ivory Coast, in March 1981 (UNEP, 1981b). Geographically, it covers the marine environment and coastal areas of the region identified by the Governments (cf. Fig. 1), the extent of the coastal area in each instance being defined according to the type of activity to be carried out. The Action Plan contains environmental assessment, management, legal, and support components. In particular it calls for the development, in the initial phase of its application, of regional activities related to contingency planning for environmental emergency cases, control of coastal erosion, and monitoring of marine pollution.

At the same conference the Convention for Cooperation in the Protection and Development of the Marine and Coastal Environment of the West and Central African Region (Abidjan Convention), and the Protocol concerning Cooperation in Combating Pollution in Cases of Emergency, were adopted and opened for signature.

UNEP was designated as the secretatiat of the action plan and of the Abidjan Convention.

\section{The East African Action Plan}

The development of an Action Plan for this Region is in a preliminary stage. $\mathbf{A}$ fact-finding mission has visited the eight East African States involved (Comoros, Kenya, Madagascar, Mauritius, Mozambique, Seychelles, Somalia, and Tanzania-cf. Fig. 1). Based on their reports and a regional workshop, a draft Action Plan will be prepared and submitted to the Governments of the region for their consideration-probably in early 1983.

\section{The East Asian Seas Action Plan}

This Action Plan was adopted at an intergovernmental meeting at Manila, Philippines, in April 1981 (UNEP, 1981c). Geographically it covers the marine environment and coastal areas of Indonesia, Malaysia, Philippines, Singapore, and Thailand (cf. Fig. 1), without prejudice to any future extension so as to cover the marine environment and coastal area of all states bordering the East Asian Seas as may be determined at a later stage.

A large number of regional projects related to environmental assessment and management of the coastal areas is envisaged by the adopted Action Plan, but in the initial phase priority will be given to those dealing with basic oceanography, control of coastal pollution, protection of mangroves and coral reefs, and waste management.

UNEP was designated as the secretariat of the Action Plan.

\section{The Red Sea Action Plan}

This Action Plan was adopted at an intergovernmental conference at Jeddah (Jidda), Saudi Arabia, in January 1976 (Ghabbour, 1976), and reoriented at a conference of plenipotentiaries held in Jeddah in February 1982 (ALECSO, in press). The Action Plan calls for the efficient conservation and management of the coastal and marine environment and its resources in the region (cf. Fig. 1).

The January 1982 conference of plenipotentiaries at Jeddah also adopted, and opened for signature, the Convention for the Conservation of the Marine Environment of the Red Sea and Gulf of Aden (Jeddah Convention), and the Protocol concerning Regional Cooperation in Combating Marine Pollution by Oil and other Harmful Substances in Cases of Emergency. Seven parties have so far signed the legal agreements.

The Arab League Educational, Cultural and Scientific Organization (ALECSO) was designated as the secretariat of the Action Plan (Red Sea and Gulf of Aden Environment Programme-acronym PERSGA) on an interim basis, i.e. until the establishment of the Regional Organization for the Conservation of the Marine Environment (as provided for in the convention) which will assume the secretariat functions for PERSGA and the Jeddah Convention.

\section{The South-west Pacific Action Plan}

Very recently (8-11 March 1982) a Conference on Human Environment in the South Pacific took place at Rarotonga, Cook Islands. It reviewed the state of the environment in the region, adopted a regional action plan (South Pacific Regional Environment ProgrammeSPREP), signed a declaration on natural resources and the environment, and endorsed the proposal for institutional and financial support for the implementation of SPREP.

The geographic coverage of the Action Plan includes the coastal waters and the adjacent coast of States and territories of the South Pacific Commission (SPC) and the South Pacific Bureau for Economic Cooperation (SPEC): i.e. American Samoa, Cook Islands, Fiji, French Polynesia, Guam, Kiribati, Nauru, New Caledonia, Niue, Norfolk Islands, Papua New Guinea, Pitcairn Island, Solomon Islands, Tokelau, Tonga, Trust Territories of the Pacific Islands, Tuvalu, Vanuatu, Wallis and Futuna Islands, and Western Samoa (cf. Fig. 1).

\section{The South-east Pacific Action Plan}

This Action Plan was adopted at a conference of plenipotentiaries at Lima in November 1981 (UNEP, 1982b). The geographic coverage of the Action Plan comprises the marine environment and Pacific coastal areas of Chile, Colombia, Ecuador, Panama, and Peru (cf. Fig. 1).

The Action Plan calls for the implementation of a large number of regional projects to assess the sources and magnitude of marine pollution and to control it through appropriate management techniques. 
The same conference adopted the Convention for the Protection of the Marine Environment and Coastal Area of the South Pacific (Lima Convention), the Agreement on Regional Cooperation in Combating Pollution of the Southeast Pacific by Hydrocarbons and other Harmful Substances in Cases of Emergency, and the institutional and financial arrangements for the implementation of the Action Plan.

The Permanent Commission for South Pacific (CPPS) was designated as the secretariat of the Action Plan and the Lima Convention.

\section{The South-west Atlantic Action Plan}

The development of an Action Plan for the Southwest Atlantic Region (coastal regions of Argentina, Brazil, and Uruguay) is in an early preliminary stage.

\section{ACKNOWLEDGEMENT}

The Authors wish to acknowledge the extensive use of the document cited as (UNEP, 1982a) in the preparation of this article.

\section{SUMMARY}

Regional marine programmes are by no means a new phenomenon, the first such activity (International Council for the Exploration of the Sea, ICES) having been in operation since 1902 . While in most cases early regional activities began as research programmes, they frequently provided a foundation for the management of marine living resources and, approaching the 1970s, for the control of marine pollution.

The 1972 United Nations Conference on the Human Environment (Stockholm) outlined a 'master-plan' for protecting the world's environment which linked environmental assessment, environmental management, and supporting measures, as basic and inseparable elements also recognizing the advantages of a regional approach in contributing to the solution of global problems. The development of UNEP's Regional Seas Programme, since the Action Plan for the Mediterranean was adopted in 1975, demonstrates that the basic concepts formulated at Stockholm can effectively foster regional cooperation among interested States, and that such cooperation can and does benefit greatly from the support of the United Nations system as a whole.

The viability of any long-term regional programme lies with the political and financial commitment of the Governments concerned. Within the UNEP Regional Seas Programme this commitment is usually formalized through binding regional legal agreements, and is manifested concretely through an agreed set of activities that are revised periodically by the Governments involved. It is expected that these activities will be adequately supported by financial resources put at the disposal of each of the regional programmes primarily by the Governments concerned.
Although the degree of coordination and cooperation achieved generally within the regional programmes reviewed in this paper appears to be satisfactory, it would be surprising if some difficulties did not arise. This is especially true because of the complexity of the venture and the fact that, in many cases, an entirely new type of cooperation is called for and new activities are required in geographical areas with often little experience, limited facilities, and weak infrastructures. For the most part the Governments, their national institutions, and the international, intergovernmental, and regional, organizations involved, are doing their best to work together effectively. Their resources are, however, often very limited, and so it is essential that they be utilized to the best possible advantage.

UNEP, as the major financial contributor to the initial phases of the action plans developed in the framework of the Regional Seas Programme, and as their overall coordinator, has a difficult task to perform if it is to see its early successes in the Mediterranean Region matched elsewhere with real action and positive results.

\section{REFERENCES}

ALECSO (in press). Final Act of the Conference of Plenipotentiaries on the Red Sea and the Gulf of Aden. ALECSO, B.P. 1120, Avenue Mohamed 5, Tunis, Tunisia.

GHABBOUR, Samir I. (1976). The 1976 Jeddah Declaration on the Red Sea and the Gulf of Aden. Environmental Conservation, 3(2), p. 122.

GLOBAL 2000 REPORT TO THE PRESIDENT (1980). Vols. $1-3$, U.S. Government Printing Office, Washington, D.C.: $47+766+401$ pp., illustr.

JOHNSON, Stanley P. (1975). Intergovernmental Meeting on the Protection of the Mediterranean. Environmental Conservation, 2(3), pp. 235-6.

RESS, Paul E. (1978). International pollution treaties in the Mediterranean, Environmental Conservation, 5(2), p. 100.

REVIEW OF THE HEALTH OF THE OCEANS (in press). Rep. Stud. GESAMP (15). UNESCO, Place de Fontenay, 75007 Paris, France.

THACHER, Peter S. (1976). Conference of Plenipotentiaries of the Coastal States of the Mediterranean Region on the Protection of the Mediterranean Sea. Environmental Conservation, 3(2), pp. 152-3.

UNEP (1975). Report of the Intergovernmental Meeting on the Protection of the Mediterranean. (UNEP/WG.2/5.) UNEP, Geneva, Switzerland: $19 \mathrm{pp}$.

UNEP (1978). Final Act of the Kuwait Regional Conference of Plenipotentiaries on the Protection and Development of the Marine Environment and the Coastal Waters. United Nations/United Nations Environment Programme, Geneva, Switzerland: $69 \mathrm{pp}$.

UNEP (1981a). Report of the Intergovernmental Meeting on the Action Plan for the Caribbean Environment Programme. (UNEP/CEPAL/IG.27/3.) UNEP, Geneva, Switzerland: $45 \mathrm{pp}$.

UNEP (1981b). Final Act of the Conference of Plenipotentiaries on Cooperation in the Protection and Development of the Marine and Coastal Environment of the West and Central African Region. (UNEP/IG.27/7.) UNEP, Geneva, Switzerland: $50 \mathrm{pp}$.

UNEP (1981c). Report of the Intergovernmental Meeting on the Protection and Development of the Marine Environment and Coastal Areas of the East Asian Region. (UNEP/IG. 26/6.) UNEP, Geneva, Switzerland: 32 pp.

UNEP (1982a). Achievements and Planned Development of 
UNEP's Regional Seas Programme and Comparable Programmes Sponsored by Other Bodies. (UNEP Regional Seas Rep. Stud. No 1.) UNEP, Geneva, Switzerland: 64 pp.

UNEP (1982b). Final Act of the Conference of Plenipotentiaries on the Action Plan for the Protection of the Marine Environment and Coastal Areas of the South-east Pacific. (UNEP-CPPS/IG.32/4.) UNEP, Geneva, Switzerland: 68 pp.
UNEP (1982c). Convention for the Protection of the Mediterranean Sea against Pollution and its Related Protocols. United Nations/United Nations Environment Programme, New York, NY, USA: 46 pp.

UNITED NATIONS (1973). Report of the United Nations Conference on the Human Environment. United Nations, New York, NY, USA: 77 pp.

\section{The Cousteau Society - Fondation Cousteau}

Created in New York City on 19 September 1973, and operational world-wide from 23 January 1974, The Cousteau Society is a non-profit, tax-deductible, non-governmental (NGO), and membership-supported organization that is dedicated to the protection and improvement of life on our planet. Similar but independent foundations have recently been launched in France (Fondation Cousteau) and Canada (Cousteau Society/ Fondation Cousteau Canada), while others are being planned in South America, Africa, and Asia.

The general spirit of the statutes provides for the following five (but often overlapping) objectives:

- To encourage and support the conservation of natural resources and the protection of all elements of the natural environment -including forests, wildlife, wilderness, parks, open spaces, rivers, oceans, and seas;

- To increase knowledge and foster appreciation of the world's natural resources and all elements and aspects of the environment;

- To sponsor and conduct research directed towards the conservation of natural resources and the pro. tection of all elements of the environment-by means of seminars, conferences, lectures, newspaper articles, expeditions by land, sea, and air, as well ultimately outer space, and by any suitable means;

- To disseminate such knowledge and the results of such researches by any and all means and media available-including publications, all forms of television, motion pictures, radio, video and sound recordings, exhibits and museums, multi-media systems, and other means of written and oral communication; and

- To cooperate with governmental, intergovernmental, and international agencies, and with charitable, educational, scientific, historical, and other organizations, in the collection and dissemination of knowledge of natural resources and the environment, and to seek the support of such and other organizations to further the above objectives.

The Society also carries on or sponsors research in fields that have little chance of being funded by governments or industry, but avoids those subjects or activities which are within the capacity or competence of national or local organizations. It aims rather at helping and contributing to the efforts of international organizations devoted to the better understanding, protection, and rational use, of the environment and its resources.

In this context, The Cousteau Society pioneered a global survey and assessment of the 'vitality' of the oceans, and plans the construction of an 'evaluation centre' to digest data made available by scientists and explorers who continuously take the pulse of the planet, as well as to monitor independently the veracity or accuracy of public announcements made by official agencies or by industry.

Furthermore, in an effort to contribute to the better understanding of some serious questions which consti- tute a major source of concern for tomorrow, The Cousteau Society, through the scientific and technological potential of its Council of Advisers, regularly undertakes exercises in the fields of marine environmental and social policies. These have culminated in the drafting of policy recommendations which relate the protection of the oceans to global as well as national needs.

A 'Bill of Rights for Future Generations' has also been elaborated for the consideration of the United Nations and its specialized agencies. The official presentation of this document is scheduled for the occasion of the celebration of the 10th anniversary of the Stockholm Conference on the Human Environment-in May and June 1982, in Nairobi, Kenya.

Recently a new project has been started on how a real and workable conversational mode can be established between three of the major constituents of our modern society-namely ecology, economy, and technology - to reach wise and widely acceptable solutions to the vital problem of preserving a liveable planet for future generations, while fostering the creation of a lastingly sound international economic order, and all despite expected further drastic increases in human population.

With a view to documenting the basic needs of such efforts and thoughts, and to getting first-hand scientific information that ultimately supports the creation of public educational and awareness material, the Cousteau Society undertakes scientific/environmental missions in endangered regions of the world. Thus a few years ago the Society's research vessel Calypso completed a survey of much of the Mediterranean basin in order to contribute, together with scientists of twelve of the eighteen Mediterranean countries, to the definition of baselines for future comparison and the possible establishment of a general monitoring system for the entire region.

Other recent investigations and surveys covered the Venezuelan coastline from the Orinoco Delta to the Venezuelan Gulf, the unique environment of Clipperton Island in the Pacific, and the regions of the Gulf of St Lawrence, the St Lawrence Seaway, and the Great Lakes.

An important new mission is now being organized to identify and study some of the long-range effects on the region of rapid developments in Amazonia, in cooperation with scientists of Amazonian countries and with the participation of specialized international organizations.

The results of such investigations also contribute to the efforts and objectives of agencies of the United Nations family, and especially to the goals of the United Nations Environment Programme (UNEP). Further direct contributions have been made or are envisaged, as in the case of the UNEP Mediterranean and Caribbean action plans. 